\title{
Out of sight, out of mind: Occlusion and the accessibility of information in narrative comprehension
}

\author{
WILLIAM S. HORTON \\ State University of New York, Stony Brook, New York \\ and \\ DAVID N. RAPP \\ Tufts University, Medford, Massachusetts
}

\begin{abstract}
Do readers encode the perceptual perspectives of characters during narrative comprehension? To address this question, we conducted two experiments using stories that sometimes described situations in which certain information was occluded from the protagonists' views. We generated two related hypotheses concerning the potential impact of occlusion events on text representations. One, the event boundary hypothesis, suggested that any salient narrative event would reduce the accessibility of prior story information. The second, the perceptual availability hypothesis, suggested that accessibility would decrease most for information no longer visible to story protagonists. In Experiment 1, the participants were slowest to respond to verification questions that asked about occluded information. In Experiment 2, we demonstrated that this effect did not extend to other, nonoccluded information. These results suggest that readers encode text information from the perceptual perspective of story protagonists. This is consistent with recent perceptual symbol views of language comprehension.
\end{abstract}

In the classic story The Strange Case of Dr. Jekyll and Mr. Hyde (Stevenson, 1885/1993), Mr. Utterson, a lawyer, travels to the home of the sinister Mr. Hyde:

As the cab drew up before the address indicated, the fog lifted a little and showed him a dingy street, a gin palace, a low French eating-house, a shop for the retail of penny numbers and twopenny salads, many ragged children huddled in the doorways, and many women of different nationalities passing out, key in hand, to have a morning glass; and the next moment the fog settled down again upon that part, as brown as umber, and cut him off from his blackguardly surroundings. (pp. 119-120)

Like many narratives, Stevenson's work mentions numerous details about the story environment, including objects visible to story characters. These details allow readers to experience the narrative vicariously, through the eyes of the protagonist (Zwaan, 1999). In the passage above, however, Utterson's view of his "blackguardly surroundings" becomes obscured by fog. Such occluding events are not uncommon in narratives: Doors close,

This material is based on work supported in part by the National Science Foundation under Grants IRI-971 1974 and (in cooperation with the Perseus Digital Library Project) IIS-9817484. We thank Nancy Franklin, Richard Gerrig, Joy Hanna, and Holly Taylor for their constructive feedback on earlier versions of this paper. We also thank Rebecca FincherKiefer, Gabriel Radvansky, and Kenneth Forster for their comments. Correspondence concerning this article should be addressed to W. S. Horton, Department of Psychology, State University of New York, Stony Brook, NY 11794-2500 (e-mail: whorton@ms.cc.sunysb.edu). people leave rooms, or objects move in front of characters. Although previous research has shown that readers readily represent information that is present in narrative situations (e.g., Glenberg, Meyer, \& Lindem, 1987), it is less clear whether they encode the consequences of events that occlude certain information. In this paper, we assess whether readers' text representations reflect the perceptual availability of information in the narrative world. We present two experiments in which participants read stories describing occlusion events. Our results are consistent with recent models of text comprehension that claim that readers closely represent the perceptual perspective of story protagonists.

\section{Situation Models and the Accessibility of Story Information}

Current theories of text processing generally assume that readers create situation models to represent information in texts (Garnham \& Oakhill, 1996; JohnsonLaird, 1983; Kintsch, 1988, 1998; van Dijk \& Kintsch, 1983; Zwaan \& Radvansky, 1998). Constructing a situation model involves integrating information stated in the text with information retrieved from long-term memory. As such, situation models represent more than the surface contents of a text; they represent what the text is about (Glenberg et al., 1987). They allow readers to encode information associated with different aspects of story situations, including the goals and intentions of characters, the causal consequences of events and actions, and the spatiotemporal relationships between char- 
acters and their surroundings (Rapp, Gerrig, \& Prentice, 2001; Zwaan, Magliano, \& Graesser, 1995; Zwaan \& Radvansky, 1998).

Because situation models reflect a reader's current understanding of the ongoing situation described by the text, a crucial feature of such models is that they are dynamic. As events occur in texts, readers update their models in order to represent new states of affairs (de Vega, 1995; Morrow, Bower, \& Greenspan, 1989). As a result, the accessibility of information can vary as story circumstances change. For example, when people read about a protagonist walking through a well-known environment, information from the protagonist's immediate location may be more accessible than information from other, more distant locations (e.g., Morrow, Greenspan, \& Bower, 1987). Similarly, the accessibility of particular discourse referents can wax and wane as story protagonists separate and reunite (Gerrig \& McKoon, 2001). Our question, then, is whether there are similar shifts in accessibility following events that occlude particular aspects of narrative situations.

\section{The Event Boundary and Perceptual Availability Hypotheses}

We wish to consider two related hypotheses concerning the impact of occlusion events on text comprehension. First and most generally, readers may simply treat any salient narrative event as a signal to shift their focus away from earlier story information. As described by Gernsbacher's (1990) structure-building account of text comprehension, changes in the topic, point of view, or setting of a story can prompt readers to construct new mental substructures in their representation of the text. One consequence of building new structures is that information from previous structures may become less accessible (Gernsbacher, 1985). To the extent, then, that new narrative events are encoded by separate mental substructures, they should mark discontinuities in the accessibility of information from texts (see, e.g., Zwaan, 1996, in which stories containing temporal boundaries and accompanying shifts in accessibility for text information were examined). We call this broad claim about the impact of narrative events the event boundary hypothesis.

Different kinds of events, however, can have particular effects on the availability of information in a text. Consider, for example, the experiment reported by Glenberg et al. (1987), in which participants read stories that created either an explicit association (He put on his sweatshirt) or dissociation (He took off his sweatshirt) between protagonists and some target object. Using the object names (e.g., sweatshirt) as recognition probes, Glenberg et al. found slower response times for dissociated items, demonstrating that readers were sensitive to whether or not information remained associated with story protagonists. Clearly, the particular consequences of narrative events affect how readers represent texts.

Thus, our second hypothesis, called the perceptual availability hypothesis, is essentially a more specific version of the event boundary hypothesis, dealing primarily with narrative events that affect the perceptual perspective of story protagonists. For example, what happens when readers encounter an event (such as the onset of a thick fog) that severs the visual link between story protagonists and portions of their narrative environment? If maintaining an accurate representation of the protagonist's point of view is an important component of situation model updating, tracking characters' moment-by-moment perceptual experiences should be central to this process (Morrow, 2001; Morrow et al., 1987; Zwaan, 1999). As a result, objects that undergo occlusion may become less accessible from readers' text representations, reflecting their reduced visual availability in the story environment. Consider how this idea might apply to the following passage:

Mr. Ranzini was sitting outside on his front stoop. He had lived on this block for over 30 years. Next door was a local playground for the children. Directly across the street was the mailbox that he used. As usual, Mrs. Rosaldo was taking her poodle for a walk. Suddenly, a large truck pulled up in front of Mr. Ranzini.

If readers are sensitive to the visual perspective of protagonists, their representation of the passage at this point should reflect the fact that the mailbox across the street has become hidden from Mr. Ranzini's point of view. What if, however, the last sentence read Suddenly, a man on a bike rode up in front of Mr. Ranzini? In this instance, the perceptual availability hypothesis would predict that the mailbox should remain relatively accessible, because it would still be visible to the protagonist. According to the event boundary hypothesis, though, the impact of the last sentence on readers' representations should be similar regardless of whether a massive truck or a much smaller bike pulls up in front of the protagonist, as long as this is interpreted as the beginning of a new event.

To test these hypotheses, we presented participants with stories describing situations in which certain objects were either blocked or visible from the protagonists' point of view. If only event boundaries matter, both story versions should similarly reduce the accessibility of prior story information. If, however, representing the perceptual experiences of story protagonists matters, accessibility should decrease most when objects are no longer visible.

\section{EXPERIMENT 1}

\section{Method}

Participants. Thirty-two students from Tufts University participated in this experiment for course credit. All were native speakers of English. Two individuals failed to follow experimental instructions, and so our analyses are based on results from 30 participants.

Materials. We wrote 24 stories that described situations in which there was the potential for some type of visual occlusion, as illustrated by the story about Mr. Ranzini. Several sample experi- 
mental stories used in our experiments are presented in Appendix A. Each story began with several sentences that introduced the central protagonist (or pair of protagonists) and the general scenario (e.g., Tony taking a Caribbean cruise, Rick and Judy on the beach). The fourth sentence always mentioned a target detail that was visible from the protagonist's current viewpoint. The fifth sentence served as a transition into the final two sentences of the story, which described an event that either blocked or did not block the protagonist's view of the target object. Examples of occluding events included doors closing, fog or smoke rolling in, or large objects interposing themselves in front of protagonists. Note that the stories never mentioned the fact that the critical information was being blocked from view, a more indirect type of dissociation than that found in the materials used by Glenberg et al. (1987), which generally involved physical attachment or detachment. In the other, nonblocking version of each story, an event occurred that would not obscure the protagonist's view of the target object-for example, doors remained open, or the room filled with a strong smell, rather than with thick smoke.

Each experimental story contained two possible test points. In the blocked and unblocked conditions, the test point appeared after the seventh sentence of each story, following the occurrence of either an occluding event in the blocked condition or an equivalent nonoccluding event in the unblocked condition. There was also a before test condition that was intended to demonstrate the ready accessibility of the critical information prior to an event boundary. In the before condition, the test point followed the fifth sentence of each story. At both test points, the story ended, and the participants were asked a probe question about the target object mentioned in the fourth sentence of the story (e.g., Was there a mailbox across the street?). For the experimental stories, the correct answer to the probe question was always yes.

Forty-eight filler stories described a similar range of situations as the experimental items, except that they never contained occlusion events or focused on the perceptual perspectives of story characters (see Appendix B for examples). By using twice as many nonperceptual filler items as experimental stories (only a third of which actually contained an occlusion event in any given version of the experiment), we hoped to prevent the readers from becoming sensitive to the perceptual nature of our experimental items. The filler stories varied in length from five to nine sentences and were followed by verification questions that asked about details mentioned anywhere from the first to the seventh sentence, depending on the overall length of the story. Filler story length and position of the source detail were varied to prevent the participants from anticipating the location of the critical information. For 12 of the filler questions, the correct answer was yes; for the remaining 36 fillers, the correct answer was no.

Design. Overall, there were three versions of each experimental story. In the blocked and the unblocked conditions, the probe question came after the critical event, which either blocked or left clear the protagonist's view of the target object. In the before condition, the probe question came before the occurrence of the critical event. We constructed three counterbalanced lists of stories, with each story appearing in a different version on each list. Each participant saw, in a different random order, one version of each experimental story along with all 48 filler stories, for a total of 72 stories. This resulted in a single-factor (occlusion condition: before, unblocked, or blocked) within-subjects design.

Procedure. The participants sat in front of a computer monitor with their hands resting on the keyboard. The experiment began with five practice stories and questions. The participants were instructed to read each story carefully, line by line, for comprehension. The sentences and probe questions were displayed in the center of the screen in standard upper- and lowercase type. Each story began with the prompt PREPARE FOR THE NEXT STORY, followed by the first line of the story. The participants read through each story at their own pace, pressing the space bar to advance between lines.
The last line of each story was followed by a warning tone and a probe question. The participants were required to press either the yes (i.e., "C") or the no (i.e., "M") key to respond and were given feedback: either CORRECT or INCORRECT. If they did not respond within 2,500 msec, the words TOO SLOw appeared. All feedback was followed by a $1,000 \mathrm{msec}$ pause before the prompt for the next story appeared.

\section{Results and Discussion}

The top portion of Table 1 presents the mean correct response latencies for Experiment 1. Because of the response deadline, we did not remove any outliers representing slow response times. Those instances in which the participants failed to meet the deadline represented $2.4 \%$ of the total data and were not included as part of our analyses.

If readers are sensitive to event boundaries, they should be relatively slow to respond to the verification questions in both the blocked and the unblocked conditions, as compared with the before condition. In addition, if readers are sensitive to the perceptual perspective of story protagonists, they should be slowest in the blocked condition. The pattern of means supports both possibilities: The participants were slower to respond to verification questions in the blocked condition $(1,650 \mathrm{msec})$ than in the unblocked condition $(1,526 \mathrm{msec})$, in which they were, in turn, slower than in the before condition (1,467 $\mathrm{msec})$. A one-way analysis of variance (ANOVA) on the mean correct verification times, with both participants $\left(F_{1}\right)$ and items $\left(F_{2}\right)$ as random variables, revealed a significant effect of occlusion condition $\left[F_{1}(2,58)=\right.$ $9.21, M S_{\mathrm{e}}=26,575, p<.002 ; F_{2}(2,46)=17.93, M S_{\mathrm{e}}=$ $11,456, p<.001]$. Planned pairwise comparisons revealed that response times in the blocked condition were reliably longer than those in the before condition $\left[F_{1}(1,58)=17.72, M S_{\mathrm{e}}=26,575, p<.001 ; F_{2}(1,46)=\right.$ $\left.34.29, M S_{\mathrm{e}}=11,456, p<.001\right]$ but that response times for the before and the unblocked conditions were not reliably different $\left[F_{1}(1,58)=1.90, M S_{\mathrm{e}}=26,575, p=.17\right.$; $\left.F_{2}(1,46)=3.40, M S_{\mathrm{e}}=11,456, p=.07\right]$. There was, however, a significant difference between the blocked and the unblocked conditions $\left[F_{1}(1,58)=8.00, M S_{\mathrm{e}}=26,575\right.$, $\left.p<.02 ; F_{2}(1,46)=16.10, M S_{\mathrm{e}}=11,456, p<.001\right]$.

Table 1

Mean Correct Verification Times (VTs, in Milliseconds) and Error Rates (ERs) by Occlusion Condition for Experiment 1 and by Occlusion Condition and Question Type for Experiment 2

\begin{tabular}{|c|c|c|c|c|c|c|}
\hline \multirow[b]{3}{*}{ Question Type } & \multicolumn{6}{|c|}{ Occlusion Condition } \\
\hline & \multicolumn{2}{|c|}{ Before } & \multicolumn{2}{|c|}{ Unblocked } & \multicolumn{2}{|c|}{ Blocked } \\
\hline & VT & ER & VT & ER & VT & ER \\
\hline \multicolumn{7}{|c|}{ Experiment 1} \\
\hline Target & 1,467 & .09 & 1,526 & .14 & 1,650 & .11 \\
\hline \multicolumn{7}{|c|}{ Experiment 2} \\
\hline Target & & & 1,502 & .13 & 1,586 & .15 \\
\hline Control & & & 1,517 & .08 & 1,495 & .14 \\
\hline
\end{tabular}


We also examined the pattern of response errors, shown in Table 1. It is possible to imagine that stories containing an occluding event would make readers' judgments about blocked objects more error prone. The pattern of error rates, however, does not support this possibility. We obtained no differences in error rates by occlusion condition $\left[F_{1}(2,58)=1.73, M S_{\mathrm{e}}=0.013, p=.19 ; F_{2}(2,46)=2.23\right.$, $\left.M S_{\mathrm{e}}=0.008, p=.12\right]$. Thus, the presence of an occluding event did not seem to unduly hamper readers' ability to respond accurately to the probe questions.

These results provide particular support for the perceptual availability hypothesis. Readers were slowest to respond in the blocked story condition, presumably because their situation models reflected the decreased perceptual availability of objects from the viewpoint of story protagonists. Note, however, that this outcome does not necessarily preclude a version of the event boundary hypothesis, because event boundaries may still have an effect even if there is no impact on the perceptual availability of story information. The fact that response times in the unblocked condition were not reliably different from those in the before condition suggests that our nonblocking story events may have been less salient, despite our efforts to make them as equivalent as possible. Moreover, it is possible that events in the blocked story versions caused all prior story information to become less accessible, regardless of whether it was specifically blocked from view. Occlusion events may create particularly prominent boundaries between story episodes that reduce the accessibility of any information prior to the event.

Thus, our second experiment was designed as a more specific test of the perceptual availability hypothesis. Recall the story about Mr. Ranzini in his neighborhood. When the large truck stops in front of Mr. Ranzini, what happens to readers' representations of other, nonblocked story information, such as the playground? The event boundary hypothesis would suggest that, despite the fact that the playground is still in the protagonist's view, its accessibility may decrease simply because it is associated with the story context prior to the critical event. If, however, readers are sensitive to whether information is perceptually available from the point of view of story protagonists, then only those aspects of the setting blocked from view by an occlusion event should become less accessible. By comparing readers' responses to questions about blocked information versus information that remained visible in the same story situation, Experiment 2 tested the specificity of the impact of visual occlusion.

\section{EXPERIMENT 2}

To evaluate whether occluding events reduce the accessibility of all text information that precedes the occlusion, in Experiment 2 we added a set of control questions that asked about story details that remained perceptually available despite the occlusion. We eliminated the before test point used in our first experiment but used the same set of target questions in order to replicate the critical difference between the blocked and the unblocked conditions from Experiment 1.

\section{Method}

Participants. Twenty-eight students from Tufts University participated in this experiment for course credit. All were native speakers of English.

Materials. The 24 experimental stories and target verification questions were the same as those used in Experiment 1, except for a few minor changes to eliminate infelicities in the original stories. For each story, we also generated an additional control question that asked about a text detail that could not be perceptually obscured by occluding events (see Appendix A for examples). As with the target questions, the correct answer to the control questions was always yes. The 48 filler stories and questions were the same as those used in Experiment 1.

Design. Overall, there were four versions of each of the 24 experimental stories, which differed as a function of occlusion condition (blocked and unblocked) and question type (target and control). We constructed four counterbalanced lists of stories, with each story appearing in a different version on each list. Each participant saw, in a different random order, one version of each experimental story and all 48 filler items, for a total of 72 stories. Experiment 2 had a 2 (occlusion: blocked or unblocked) $\times 2$ (question type: target or control) within-subjects factorial design.

Procedure. The procedure was identical to that in Experiment 1.

\section{Results and Discussion}

The bottom portion of Table 1 presents the mean response latencies for Experiment 2. Because of the response deadline, we did not remove any outliers. The participants failed to respond before the deadline $2.2 \%$ of the time, and these responses were not included as part of our analyses.

As can be seen in Table 1, when probe questions were about potentially blocked objects, the participants took $84 \mathrm{msec}$ longer to respond following an occluding event, as compared with when the story did not contain such an event. For the control questions, however, response latencies in the blocked condition were $21 \mathrm{msec}$ shorter than those in the unblocked condition. Analyses of the mean correct verification times revealed that although neither the main effect of occlusion condition nor that of question type was significant, the critical interaction between occlusion condition and question type was reliable $\left[F_{1}(1,27)=\right.$ $6.66, M S_{\mathrm{e}}=11,709, p<.02 ; F_{2}(1,23)=9.26, M S_{\mathrm{e}}=6,776$, $p<.006]$. To examine the critical comparisons, planned contrasts between the unblocked and the blocked conditions were carried out separately for the target and the control questions. The difference between the blocked and the unblocked conditions for the target questions was highly reliable $\left[F_{1}(1,27)=10.09, M S_{\mathrm{e}}=11,709, p<.004\right.$; $\left.F_{2}(1,23)=10.79, M S_{\mathrm{e}}=6,776, p<.004\right]$, but the difference for the control questions was not (both $F_{\mathrm{S}}<1.05$ ). This pattern replicates the increase in response times after occluding events from Experiment 1 and also provides evidence against the possibility that occlusion had a generalized impact on readers' story representations. Thus, readers appear to update their discourse represen- 
tations according to the specific visual perspective of story protagonists, in line with the perceptual availability hypothesis.

As in Experiment 1, we also analyzed the pattern of errors to assess whether the occurrence of an occluding event made the participants more prone to errors in answering questions about occluded objects. The participants were generally more likely to make mistakes in the blocked condition than in the unblocked condition, especially for the control questions. However, ANOVAs carried out on the proportions of errors revealed that the interaction between occlusion condition and question type was not significant $\left[F_{1}(1,27)=1.25, M S_{\mathrm{e}}=0.01\right.$, $\left.p=.27 ; F_{2}<1\right]$. Also, neither the main effect of occlusion condition nor that of question type was reliable. Thus, we can again conclude that there is no impact of occlusion on response accuracy.

\section{GENERAL DISCUSSION}

The goal of these experiments was to demonstrate that readers encode information about the perceptual availability of objects on the basis of the visual perspective of story protagonists. In Experiment 1, the participants were slower to respond to verification questions that asked about information that had been occluded. Experiment 2 replicated this finding and, importantly, demonstrated that this occlusion effect did not extend to unblocked information also present in the story context. Rather than always responding to event boundaries in a generalized fashion, readers appeared to incorporate the specific consequences of an object's occlusion into their ongoing text representations. Taken together, these two experiments support the perceptual availability hypothesis: Readers adjust their representation of a text to reflect the fact that protagonists no longer have visual access to particular information.

This result is particularly striking when one considers the nature of the occlusion events used in our stories. Nothing in the narratives stated that the target information was no longer visible; readers had to derive this fact from their knowledge of the real-world consequences of visual occlusion. Again, this contrasts with the materials used in Glenberg et al. (1987), in which the dissociation of objects from characters was explicit. Also, the relationships between the protagonists and the target objects in our stories were relatively incidental; there were no narrative consequences of these objects' disappearing from view. The fact that readers were still sensitive to the perceptibility of this information suggests that they readily encoded protagonists' visual perspectives into their text representations.

Discussions of text processing have frequently described narrative understanding as a process of becoming immersed in a story world (Duchan, Bruder, \& Hewitt, 1995; Gerrig, 1993; Zwaan, 1999). One consequence of such immersion may be that readers encode story information as if they themselves were actually experiencing the narrated events (Morrow, 2001). Previous experiments have provided evidence consistent with this notion. For example, Bryant, Tversky, and Franklin (1992) showed that readers' spatial situation models conform to how humans normally experience the perceptual worldnamely, objects to the front of story protagonists were recognized more quickly than those to the back or sides when readers adopted a story-internal perspective. Readers also notice when texts contain details that are perceptually inconsistent with the perspective they are using to understand the story (e.g., O'Brien \& Albrecht, 1992). Thus, sensitivity to the consequences of visual occlusion may be yet another aspect of understanding texts from the point of view of story protagonists.

How might information about visual perspective be represented in readers' discourse models? Although traditional accounts of text processing have assumed that abstract, propositional representations are invoked during comprehension (e.g., Kintsch, 1988; van Dijk \& Kintsch, 1983), recent work has suggested that analogue, imagistic representations may be better suited for mediating particular aspects of situation models (e.g., FincherKiefer, 2001; Glenberg, 1997; Stanfield \& Zwaan, 2001). Within psycholinguistics, the notion that language understanding may be rooted in perception can be traced back at least as far as Miller and Johnson-Laird (1976). Thus, when confronted with a text describing a physical environment with a particular spatial layout, readers may readily generate an analogue representation of that environment to track a character's movements. Although the results reported here provide no direct evidence concerning the use of imagery, they are consistent with the claim that readers instantiate their knowledge of the physical characteristics of situations through some type of unconscious, perception-based mental simulation (Barsalou, 1999; Glenberg, 1997; Glenberg et al., 1987). To the extent that these perceptual simulations represent the situation described by the text, the reduction in accessibility of occluded information would simply be an outcome of readers' perception-like encoding of story events.

Thus, the present results converge with a growing body of evidence showing that readers represent story events in a manner similar to actual perception. Although further evidence is needed to assess the strength of this claim, it appears that readers can behave as if they are directly experiencing the situation described by the text (Allbritton \& Gerrig, 1991; Gerrig, 1993; Zwaan, 1999). As we have shown, this may include the encoding and retrieval of information from the visual perspective of story protagonists. Such engagement with a text may be what allows readers to experience Mr. Utterson's apprehension as he approaches Mr. Hyde's residence through the fog; after all, what he can't see might very well hurt him.

\section{REFERENCES}

Allbritton, D. W., \& Gerrig, R. J. (1991). Participatory responses in prose understanding. Journal of Memory \& Language, 30, 603-626. Barsalou, L. W. (1999). Perceptual symbol systems. Behavioral \& Brain Sciences, 22, 577-609. 
Bryant, D. J., Tversky, B., \& Franklin, N. (1992). Internal and external spatial frameworks for representing described scenes. Journal of Memory \& Language, 31, 74-98.

DE VEGA, M. (1995). Backward updating of mental models during continuous reading of narratives. Journal of Experimental Psychology: Learning, Memory, \& Cognition, 21, 373-385.

Duchan, J. F., Bruder, G. A., \& Hewitt, L. E. (1995). Deixis in narrative: A cognitive science perspective. Hillsdale, NJ: Erlbaum.

FinCHER-KIEFER, R. (2001). Perceptual components of situation models. Memory \& Cognition, 29, 336-343.

GARnhAM, A., \& OAKHILL, J. (1996). The mental models theory of language comprehension. In B. K. Britton \& A. C. Graesser (Eds.), Models of understanding text (pp. 313-339). Mahwah, NJ: Erlbaum.

GERnSBACHER, M. A. (1985). Surface information loss in comprehension. Cognitive Psychology, 17, 324-363.

GernsBACher, M. A. (1990). Language comprehension as structure building. Hillsdale, NJ: Erlbaum.

GeRRIG, R. J. (1993). Experiencing narrative worlds. New Haven, CT: Yale University Press.

Gerrig, R. J., \& McKoon, G. (2001). Memory processes and experiential continuity. Psychological Science, 12, 81-85

Glenberg, A. M. (1997). What memory is for. Behavioral \& Brain Sciences, 20, 1-55.

Glenberg, A. M., Meyer, M., \& Lindem, K. (1987). Mental models contribute to foregrounding during text comprehension. Journal of Memory \& Language, 26, 69-83.

Johnson-LAIRD, P. N. (1983). Mental models: Towards a cognitive science of language, inference, and consciousness. Cambridge, MA: Harvard University Press.

KinTSCH, W. (1988). The role of knowledge in discourse comprehension: A construction-integration model. Psychological Review, 95, 163-182.

Kintsch, W. (1998). Comprehension: A paradigm for cognition. Cambridge: Cambridge University Press.

Miller, G. A., \& Johnson-Laird, P. N. (1976). Language and perception. Cambridge, MA: Harvard University Press.

Morrow, D. G. (2001). Situation models and point of view in narrative understanding. In W. van Peer \& S. Chatman (Eds.), New perspectives on narrative perspective (pp. 225-239). Albany: State University of New York Press.

Morrow, D. G., Bower, G. H., \& Greenspan, S. L. (1989). Updating situation models during narrative comprehension. Journal of Memory \& Language, 28, 292-312.

Morrow, D. G., Greenspan, S. L., \& Bower, G. H. (1987). Accessibility and situation models in narrative comprehension. Journal of Memory \& Language, 26, 165-187.

O'Brien, J. E., \& Albrecht, E. J. (1992). Comprehension strategies in the development of a mental model. Journal of Experimental Psychology: Learning, Memory, \& Cognition, 18, 777-784.

Rapp, D. N., Gerrig, R. J., \& Prentice, D. A. (2001). Readers' traitbased models of characters in narrative comprehension. Journal of Memory \& Language, 45, 737-750.

Stanfield, R. A., \& ZWAan, R. A. (2001). The effect of implied orientation derived from verbal context on picture recognition. Psychological Science, 12, 153-156.

Stevenson, R. L. (1993). The strange case of Dr. Jekyll and Mr. Hyde. In I. Bell (Ed.), Robert Louis Stevenson: The complete short stories, (Vol. 2, pp. 102-164). Edinburgh: Mainstream Publishing. (Original work published 1885)

van DiJK, T. A., \& Kintsch, W. (1983). Strategies in discourse comprehension. New York: Academic Press.

ZWAAN, R. A. (1996). Processing narrative time shifts. Journal of Experimental Psychology: Learning, Memory, \& Cognition, 22, 11961207.

ZWAAN, R. A. (1999). Situation models: The mental leap into imagined worlds. Current Directions in Psychological Science, 8, 15-18.

Zwaan, R. A., Magliano, J. P., \& Graesser, A. C. (1995). Dimensions of situation model construction in narrative comprehension. Journal of Experimental Psychology: Learning, Memory, \& Cognition, 21, 386-397.

ZwAan, R. A., \& Radvansky, G. A. (1998). Situation models in language comprehension and memory. Psychological Bulletin, 123, 162-185.

\section{APPENDIX A \\ Sample Experimental Stories Used in Experiments 1 and 2}

The experimental stories always ended at the probe question. In the before condition (Experiment 1 only), the probe question came after Sentence 5. In the blocked and unblocked conditions (Experiments 1 and 2), the probe question came after Sentence $7 \mathrm{a}$ or $7 \mathrm{~b}$, respectively.

(1) Russ was in the hospital recovering from minor surgery.

(2) In the bed next to him was an older man named Marty.

(3) A television was attached to the ceiling between them.

(4) At Marty's side was a tall vase of flowers. (target information)

(5) Russ's friends had only given him a get-well card.

Blocked story continuation

(6a) A nurse came in and drew the curtain around Marty's bed.

(7a) She wanted privacy while she did an examination.

\section{Unblocked story continuation}

(6b) A nurse came in and attached a monitor to Marty's bed.

(7b) She needed to take his blood pressure.

Target question (Experiments 1 and 2): Did Marty have a vase of flowers?

Control question (Experiment 2 only): Was a television attached to the ceiling?

(1) James was trapped in a burning building.

(2) Hunched on the floor of his office, he feared for his life.

(3) Against his back he could feel the hard steel of his desk.

(4) His papers were scattered on the floor in front of him. (target information)

(5) The alarm bells were ringing in his ears. 


\section{APPENDIX A (Continued)}

(6a) The room quickly filled with a thick wave of smoke.

(7a) James pressed his shirt sleeve to his mouth and nose. (6b) The room quickly filled with a strong burning smell.

(7b) James pressed his shirt sleeve to his mouth and nose.

Target question (Experiments 1 and 2): Were James' papers scattered on the floor?

Control question (Experiment 2 only): Was James on the floor of his office?

(1) Mary and Bill were in their kitchen, enjoying the weather.

(2) A nice breeze was coming in through the back doorway.

(3) The smell of bread in the oven was making them hungry.

(4) Outside, a robin was splashing around in a puddle. (target information)

(5) Their peace, however, was disturbed by a buzzing fly.

Blocked story continuation

(6a) Mary got up and closed the back door.

(7a) She said she didn't want bugs in the house.
Unblocked story continuation

(6b) Mary got up and closed the screen door.

(7b) She said she didn't want bugs in the house.

Target question (Experiments 1 and 2): Was a robin splashing in the puddle?

Control question (Experiment 2 only): Was there bread in the oven?

(1) Melanie ran downstairs and threw herself onto the couch.

(2) An exciting horror movie was on television.

(3) She opened a bag of chips and dug right in.

(4) She watched a vampire stalk the helpless victim. (target information)

(5) She had never seen this movie before.

\section{Blocked story continuation}

(6a) Melanie's mother appeared in front of the TV. (7a) She told Melanie not to forget about her homework.

\section{Unblocked story continuation}

(6b) Melanie's mother appeared behind the TV. (7b) She told Melanie not to forget about her homework.

Target question (Experiments 1 and 2): Was the victim being stalked by a vampire?

Control question (Experiment 2 only): Did Melanie open a bag of chips?

\section{APPENDIX B Sample Filler Stories}

The 48 filler stories varied in length from five to nine sentences. Twelve were followed by yes probe questions, while 36 were followed by no questions.

(1) Vicki had a soft spot in her heart for stray animals.

(2) She was always bringing home lost pets.

(3) She already had several cats and four dogs.

(4) Her most recent addition was an injured spaniel.

(5) Vicki found it by the side of the road.

(6) She named the hurt dog Misty.

Question: Did Vicki already have four dogs? (Yes)

(1) Carlos enjoyed tutoring younger children in math.

(2) Every Saturday he went to the local youth center.

(3) There he spent two hours as a math tutor.

(4) His favorite pupil was a kid named Ricky.

(5) Ricky was having trouble with geometry.

(6) So Carlos brought some brightly colored shapes.

(7) He used the shapes to demonstrate different angles.

(8) However, Ricky seemed more interested in playing.

Question: Was the tutoring held on Sunday? (No) 